\section{Traditional Conflict Resolution Mechanism in Ethiopia}

\section{Million Esho Dezo}

Gilgel Beles College of Teachers Education, Department of Civics and Ethical Education, Ethiopia Email: millioneasho@gmail.com

\begin{abstract}
:
The study examines the role of Enashma traditional conflict resolution mechanism in handling conflict to maintain peace and stability. To realize the intended objectives, the study utilized case-study research approach with qualitative research method and the data were collected using observation, interview, focused-group discussion and document analysis. The data collected were analyzed and interpreted through word description and narration. According to the data obtained from the interview and focus group discussion, Enashma traditional conflict resolution mechanism has several advantages over the state law. Some of the advantages are restorative capacity, accessibility, revealing crime committed without witness and its acceptability. Paradoxically, the exclusion of women in the system, no standardized mechanism to fix payment of compensation for different conflicts, lack of supportive and strengthening measures from the government and lack of office for local elders are the major weakness of the institution as the information obtained from key informants. Therefore, the study recommended that all the stakeholders should be responsible tosolve the weakness of Enashma traditional conflict resolution mechanism in the study area.
\end{abstract}

Keywords:

Enashma; conflict; resolution; customary laws

\section{Introduction}

Conflict is not a new phenomenon in the history of human beings. It always exists as long as human beings live together, and it is an inescapable human experience. Conflict can be understood as engagement in a fight or possible confrontation between two or more parties as aspiring towards incompatible or competitive means or ends. Conflict may be either manifest, recognizable through actions or behaviors, or latent, in which case it remains dormant for some time, as incompatibilities are unarticulated or are built into systems or such institutional arrangements as governments, corporations, or even civil society (Miller, 2005)

Conflict is part and parcel of the nature of human beings. It is a fact of life. There is only one human being which is free of conflict that is a dead human being. Conflict is an inevitable phenomenon that cannot be avoided in human society's sphere of life since the entire life of humankind is manipulated by the prevalence of conflict within the society when people set opinion against opinion, run interest against interest. Wherever people interact, there is a potential for conflict. That is not bad news because good things can rise, and relationships can be improved through conflict (Galtung and Jacobsen, 2002).

Conflict can be prevented and managed by adhering to the values and principles of the constitution and other laws, and identifying the common shared values interest and goals and working together on common problems. There are two ways of conflict resolution methods, i.e. the formal and informal. The formal method is conducted in the court through litigation with official recognition of the government and tends to be more strictly examined and 


\section{Lakhomi Journal: Scientific Journal of Culture \\ ISSN: 2774-311X (Online), 2774-4728 (Print)}

Vol. 2, No. 1, March 2021, Page: 35-45

Email: lakhomijournal@gmail.com

monitored whether there are signs of impartiality, entrenched inequities and lack of due process. Informal method or sometimes called indigenous conflict resolution method is the ancient set of practices in almost all the societies in the world with an ultimate application of third party arbitration and mediation(Abraham and Yasin, 2000).Ethiopia is a country in which various ethnic groups live together for long period of time. Each group has its own indigenous mechanisms for solving conflicts. Accordingly, Benišangul-Gumuz Regional State is the home of many multilingual and multicultural societies who have their own varieties of customary practices which referred among some scholars as 'museum of culture' (Abebe, 2002).

The Boro-Shinasha community is one of the communities in Benišangul-Gumuz Regiona State, which has its own varieties of customary practices. Among these practices they have traditional conflict resolution mechanisms which are more than helping people to build solidarity and peaceful coexistence among them. It has a gap filling role for the state made laws. In BoroShinasha community, traditional conflict resolution mechanisms are known by variety of names, but they do have common goal i.e. resolving the conflicts especially personal and family peacefully through mediation, conciliation, and arbitration mechanisms. Enashma is the most known and practiced traditional mechanisms with local jurisdiction. Thus, this study is intended to explore the role of Enashma as traditional conflict resolution mechanismin Boro-Shinasha community in handling any sort of conflict in BGRS with particular emphasis on Metkel Zone, Bullen Woreda.

\section{Research Methods}

This study is conducted in Bullen woreda, Benishangule- Gumuz Regional State. This section gives a brief description of the study area. The information provided in this section include: background information on the geographical setting and climatic conditions of the study area; brief historical background of the Boro-Shinasha; major livelihood strategies; some background on socio - cultural systems of Boro-Shinasha community.

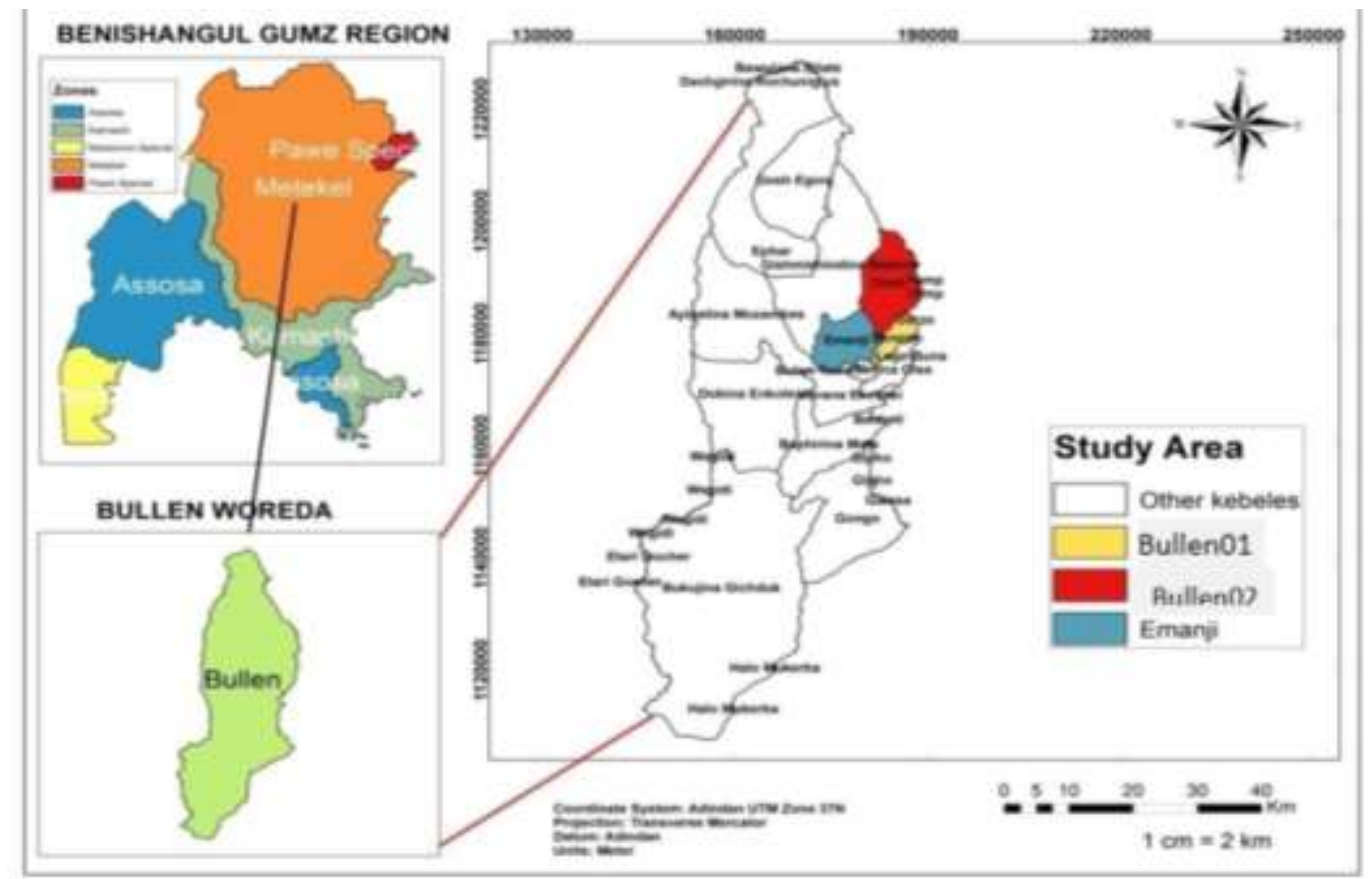

Source: Ethiopia Central Statistical Agency, 2007 
Researcher identify three different approaches to the social science research: qualitative, quantitative and mixed method. In order to attain the intended objectives of the study, the researcher employed qualitative method particularly a case study approach for its appropriateness to explore the role of Enashmainstitutions in resolution of conflicts among the Boro-Shinasha community in the study area.Qualitative approach is selected because of its very helpful contribution to gather firsthand and rich ethnographic information, and to understand the social, economic, political and religious life of the society. Beside, qualitative research is preferable in order to collect data about human life realities, experiences, behavior, emotion and feeling, organizational function, social movement and cultural phenomena. The data for the study were collected purposively at Bullen, woreda of Metkel zone, Benišangul-Gumuz Regional State.

\section{Results and Discussion}

The understanding of conflict differs from society to societydepending on the values, customs, traditions, history and geographical location, economic andpolitical situations. Although conflict is a common phenomenon in every human interactions, its types as well as its causes may vary from one society to the other. In some societies,economic factors are the major sources of conflict and in others socio-cultural and politicalfactors are the dominant causes. Regardless of how the society perceives a conflict and whateverthe causes of conflict; every society has its own institutions of conflict resolution mechanismwhich is rooted in the sociocultural, political and religious life of the society.

\subsection{Types and Sources of Conflict in the Study Area}

Conflict is natural and cannot be avoided but it is possible to minimize it. The type of Conflict is varying from place to place, from society to society and it is also different based on the type of socio-economic activity of a given society. The cause of conflict in one area may not become a cause for other area. But there are common issues that become causes of conflict elsewhere. This includes political, social and economic issues (Bamlak, 2003).

The data gained from interview and the focus group discussion participants indicates that, the common types and causes of conflict observed among the Boro- Shinasha communities are land and land related, marital related, physical violence, inheritance related, theft, robbery, breach of agreement and trust, insulting and evil-eye. Similarly, conflict occur in North West parts of Ethiopia along Boro-Shinasha communities due to dispute over land, conflict over martial issues, conflict over property, cattle theft, abduction, physical violence, belief in an evileye and adultery(Abebe, 2012). Hence, the common types of conflict observed in the study are includes; interpersonal, intra-family, inter-family, intra-ethnic and inter-ethnic conflict.

According to the information collected fromBullen Woreda court and police annual reports of the last two years, land related, marital related, physical violence, theft, inheritance and breach of agreement are the major conflicts that occurred frequently in the area. The following table shows the causes and the magnitudes of conflicts that are presented to the police and court in the last two years. 
Table 1. Civil and Criminal Cases Taken to the Bullen Woreda Court and Police in the Last Two

\begin{tabular}{|l|l|l|l|l|}
\hline \multirow{2}{*}{ No } & Types and Cause of conflict & \multicolumn{3}{|c|}{ Years } \\
\cline { 3 - 5 } & & 2008 & 2009 & Remark \\
\hline 1 & Land related conflicts & 458 & 449 & \\
\hline 2 & Marital & 358 & 325 & \\
\hline 3 & Physical violence & 30 & 29 & \\
\hline 4 & Inheritance related & 248 & 181 & \\
\hline 5 & Theft & 42 & 39 & \\
\hline 6 & Homicide & 10 & 7 & \\
\hline 7 & Attempted to homicide & 9 & 15 & \\
\hline 8 & Breach of agreement and trust & 26 & 23 & \\
\hline 9 & Robbery & 10 & 6 & \\
\hline 10 & Illegal trade & 9 & 13 & \\
\hline 11 & Corruption & 2 & 1 & \\
\hline 12 & Insulting & 15 & 18 & \\
\hline 13 & Rape and Abduction & 5 & 2 & \\
\hline 14 & Early Marriage & 8 & 8 & \\
\hline 15 & Widow Marriage & 3 & 4 & \\
\hline 16 & Others & 36 & 29 & \\
\hline Total & 1259 & 1149 & \\
\hline
\end{tabular}

Source: Bullen woreda court and police reports of 2016 and 2017

The above table shows the various causes of conflicts and its prevalence. These could becategorized into civil and criminal cases. According to informants, most civil cases are usuallyhandled at Enashma traditional conflict resolution institution and majority of these type of conflict do not present before thecourt. Therefore, the magnitude of civil cases reported to the court might not show the realoccurrences of such types of cases.

The data gained from the woreda court and police reports indicate that the primarycause of conflict in the study area is in the area of economic interest, especially land relatedconflicts. The economic causes of conflict include conflict over land ownership right, claimingtracts of adjacent farm land, grazing land, inheritance, theft and marital conflict involving right to property. Other causes ofconflict like physical violence, breach of agreement, false witnesses, committing adultery and raping which areassociated with other socio-cultural or economic factors are also prevalent. These types ofconflicts are usually taken to Enashma traditionalconflict resolution institution to be settled.

Case: The following case shows conflict over adultery and get resolved at Enshma institution particularly at Sher Dameya.

As key informant elders asserted, $\mathrm{Mr} A D$ caught his wife committing adultery with $B D$. In the emotion of the moment, he immediately picked up his knife and killed Mr. BD. Then, he went to the police and reported the case. The police investigated the death and arrested AD. He was sent to detention center for about fiveyear while the police completed their investigation and the court check evidence to prove his guilt beyond reasonable doubt. Finally, he was released after seven years from the prison. However, after he had been released, he went to the Nihinaa and told him the truth. Then, the Nihinaa gave $A D$ an interruption and sent letters inviting two other elders from the Endibo and Enoro clans to participate in resolving the conflict. He also requested the relatives of both of the dead 
to participate. The dispute was dealt with according to the customary practice. After considering the facts of the case thoroughly; even if, he should be exile for seven up to eight years according to the norms and principles of the community $A D$ was sent into exile for 1 year. After completing this period of exile, he returned to the community. In making this decision the values and norms in that specific society were considered. Adultery is seriously condemned. Therefore, the period of exile was not for the purpose of punishing $A D$, but rather to reconcile him and his relatives with the relatives of the deceased.

\subsection{Enashama Traditional Conflict Resolution Mechanisms in Boro-Shinasha People}

Enashma traditional conflict resolution system is the widely used institution of conflict resolution of Boro-Shinasha in the study area. The term Enashma refers to the process of conflict resolution through the useof Eneshas (elders). Eneshasare those elderly individuals of the society who mediate and solve conflict cases.Although the term 'Enesha' literally mean 'elderly' refers to old age, in the context of conflictresolution one should not necessarily be of old age to be recruited as Enesha. Instead, the termEnesha is used more as a symbol here. In connection with this informants stated that among theBoro-Shinasha, elderly members of the community are respected for their knowledge of customary lawsand are perceived as symbols of wisdom, peace and reconciliation. As informants further argued, it isbecause of this symbolic significance of the elderly that any person who is involved in conflictresolution and reconciliation process is called Enesha regardless of his actual age.Therefore, a young adult man could be considered by the society as Enesha as there is norestriction of age to be Enesa. What is crucial to assume the position of Enesha is his knowledge on how to resolve conflicts, forinstance, his rhetorical ability in the search for aro (truth), his ability to articulate andpoliteness and carefulness not to provoke the parties in conflict. The Eneshasknow the norms ofthe society, they are impartial and have a wealth of experience. They also hold fair publichearing and make decision.

Focus group participants and one of the Boro-Shinasha development association high expert explained that the Boro-Shinasha people primarily use traditional mechanism to resolve any types and causes of conflicts among themselves. They have a well established traditional court-like system known as Enashma. This system has four hierarchical structures. These are:

Burra: This is conducted by three elders. When the disputant(s) is dissatisfied with the decisions of the Burra, they are allowed to make an appeal to the Nemma.

Nemma: This is composed of three elders. Nemma has the power to ratify or denounce or amend decisions made by the Burra. If either of the disputants is still dissatisfied after the decisions of the Nemma, they may bring the case to the Terra/Tsera.

Terra/Tsera: This is composed of one elder. The elder examines the decisions made by the Burra and Nemma and speaks to each of the disputants separately before making their decision. The decision made by the terra is final and binding.

Falla/ Shire Dameya: This is the only court which handles homicide cases and cases of sexual intercourse between relatives. It is the final or highest 'judicial' organ in Shinasha. A single person from the 'tribal' clan, called Nihinaa, holds the position of Falla. When considering a dispute, the Nihinaa is assisted by two neutral persons who are not decision makers. The decision made by theNihinaa is final and binding. 


\subsection{The Process of Enashma Traditional Conflict Resolution Mechanism and the Major}

Actors

In this section attempts have been made to discuss the process, enforcement and actors in Enashma conflict resolution process and customary laws actors used.

\section{a. The Process of Enashma Traditional Conflict Resolution Mechanism}

The conflict resolution of the Boro-Shinasha community involved elders and blood fathers to solve minor disputes in the context of traditional law; in case of the Boro-Shinasha ethnic groups, this system is called Enashma which is governed by an unwritten law that is transmitted from generation to generation orally. Theinstitution leads by elders whose number varies between one and three without the participation of women as elders but male youths. And elders, in this institution, would be elected with the consent of the contestants. After selection of elders, elders would move to deal with the conflicting cases (dispute arise over issues like land owner ship, maternal issues, insult, quarrel over boundaries, denial of contracts, causing bodily injures, evil-eye and murder).

However, among this society, not all conflicts need the involvement of third party like elders; rather sometimes individuals would try to resolve their conflicting issues using the mechanism of negotiation. For instance, conflicts between spouses and families could be resolved through negotiation without inviting third party. Besides, if the conflict is caused by property destruction, the conflicting parties may negotiate. That is, the one who committed crime may agree to compensate the victim. However, sometimes conflicting cases may not be resolved using negotiation mechanism. Then, when facing such problems of failing to resolve using negotiations, conflicting parties refer their case to elders. That is, if the conflicting parties failed to resolve their conflicting case, they would select their own elders (Eneshas) who could help them resolve their differences.

The elders have certain procedure of hearing cases. The plaintiff and the defendant come in front of the Eneshas(Elders) and present their case bystanding there. The plaintiff stands on the right side, and presents his/her case first. While oneparty is speaking the other party is expected to listen carefully for which he/she responds laterand not to speak against. The defendant, who stands on the left side, is the second to presents his/her case. After hearing the cases, the Eneshas may ask both parties turn by turn forclarification. Besides, if the case needs further investigation and one or the two parties obscurethe truth, the Eneshas try to convince one party by sending the other away. In this process, they use their personal skills and knowledge of cultural norms, values and custom and warn theparty by referring to customary laws. As they identified the basic cause of the conflict, Eneshas require both parties to stay awayfrom them for a moment. During this time, they discuss what they have observed, including whatthey knew before, and propose the possible solution. Then, the parties are called and theproposed decision is presented to them, with detail explanation and advice. If the parties aresatisfied with the decision, the reconciliation process would take place. The settlement process often involves oath-taking rituals, making of pledges to honor agreement reached andpayment of compensation by the wrong-doer. Finally, the culmination of the reconciliation ceremony the Eneshaslet the two parties to shake hands with each other and kiss one another. Then, the conflict parties swear oaths as a sign of joint commitment to peace and reconciliation. 


\section{b. Actors Involved in Enashma Traditional Conflict Resolution Institution}

Actors who involved in Enashma traditional conflict resolution institution of BoroShinasha community includes: Eneshas (community elders), Nihinaa (Blood Father), Iq Niha (Religious leder)and women.

\section{The Eneshas (The Elders)}

Based on the data obtained by interviews, when the dispute raised over the matters such as land and land related, maternal related, theft, abduction and evil-eye; the Boro-Shinasha community are solved through Eneshas (elders). The Eneshas emphasizes on the interest of the conflicting parties in their decision making process. Eneshas monitor and influence grass root opinions of the disputants and they act as mediators operating in open assembly not secretly. They work on the basis of enlightened conflicting parties interest to produce necessary and crucial results through customary laws of Enashma institution and the customary laws bound to bring behavioral and social change there by maintaining their relations and managing the conflict.

\section{The Nihinna (The Blood Father)}

According to the information obtained from key informants, the Niihinnas is visible as other actor that is involved in resolving conflict through Enasham traditional conflict resolution institution. He is the great descendent of the king line. Thus, he is highly respected and feared by the community. He participate as a mediator for the high level of conflict cases like life losses or killing a person and cases of sexual intercourse with relatives.

\section{The Iq' Nihas (Religious Elders)}

As per the information obtained from focus group discussion, religious leaders are other actors that are participating as a third party in Enashma traditional conflict resolution system. The community considers the Iq' Nihas as those who can act on behalf of the will of God and who could argue for truth. No one expects them to speak false because they are God envoys who are respected, trusted and have got high position by the society. Leaders of religious institution thought the society about the disadvantage of conflict. That means they thought their followers as conflict is bad and that killing or wishing to kill a person were strictly forbidden in the eyes of God and this isolates them from heaven. Finally, the Iq' Nihas bring the conflicting parties into agreement to reconcile their antagonistic idea.

\section{The Women}

According to the information acquired from focus group discussion, women have an indirect but important role in conflict resolution process of Enasham institution. The informant said that, women must be respected as they have pivotal role inEnashma traditional conflict resolution process; and further argue that they should involve peace promotion and peacemaking in Boro-Shinasha community.

\section{c. Customary LawsUsed inEnashma Traditional Conflict Resolution Institution}

Actors in Enashma traditional conflict resolution institution are guided by specific rules and procedures rooted in the history and culture of the society referred to as Nemma (custom)and Terra (laws) as the data obtained from interview. Nemma is a general term to refer to way of life or culture in general and Terra is the specific concept that related with rules and regulation. These laws have legal characteristics that govern the activities of individuals. Though they do not exist in printed copy, the specific rules and procedures governs and manages the activities of individuals. The Boro-Shinasha community resolves conflicts, identify and penalize wrong doer, enforce decision, make reconciliation and, thereby ensure the peaceful and harmonies of the societyby using Nemma and Terra (customary law). These customs and laws 
(Nemma and Terra) are put in to practice by the Enashma traditional institution of conflict resolution among the Boro-Shinasha people. Most of the time, actorsare guided by customary laws in dealing with conflicts.

\section{d. The Enforcement of Decisions Made by Enasham Traditional Conflict Resolution Institution}

Unlike in modern justice systems, Enashma traditional conflict resolution usually lacks the machinery toenforce judgments unless the disputant voluntarily accepts the penalty imposed. In Boro-Shinasha society the disputantsguarantee that the decision of the Eneshas or Nihnnawill be carried out. The community ostracizes a member who refuses to respect the decision of the elders and Nihnna. Thus, Social sanction is at the centreof the decision-enforcement mechanism, and ostracism is very common.

The data obtained from the interview also demonstrated that; when a person refuses to accept the final decision of the elders, they will be subjected to Tsala (ostracism or stigmatization). This includes the following: the roof of the house which the person lives will be uncovered by the society in order to penalize him by sunshine and rainfall.The wife and children of the refusing person will not be allowed to socialize/communicate with the neighbors and the society in their daily life.The person will be prohibited from participating in the traditional collaborative system of agriculture, Dawa (Debbo). If the refusing person migrates to other areas to live, delegates will be sent to the area by the elders to inform the elders of that area about the disobedience. So the person will be obliged to return to his original place and ask the elders for mercy. The person is expected to ask forgiveness by holding a bone in his mouth and saying to the elders 'I will be subject to you like a dog.' After this, elders will give mercy to him and he will again be allowed to socialize with community and the roof of his house will be covered and returned to its initial place. He is expected to tolerate the penalties and pay the compensation decided by elders.

\section{Conclusion}

The study explored and examined the types and causes of conflicts as well as Enashma traditional institution of conflict resolution among Boro-Shinasha of Bullen woreda. My finding reveals that, the common types of conflicts that usually take place and resolved through Enshama traditional conflict resolution mechanism in the study area are inter-personal, intragroup and inter-group in nature. My finding also exposes source of conflicts in the study area is generated by economic and socio-cultural matters which are based on human interaction. As the data obtained through interview, observation and focus group discussion conflict is activated by different sources in study site. Of the major cause of conflict among the Boro-Shinasha, the lion share is taken by land and marital related issues. Conflict over farmland boundary, the use of other's grazing land dishonestly, dispute over the use of communal grazing and forest land, displacement and remove of boundary marks, claim of land ownershipare the common causes of land related conflicts. On the other hand, Conflict between married couples over resource administration and polygamy are the common causes of marital conflict in the study area.Theft, physical violence, breach of agreement, false witnesses, evil-eye, committing adultery and raping are also causes of conflict in the study area.

The working relationship between the Enashma traditional conflict institutionand formal court institution is attractive. The formal court structures refer the case to Enashma institution and needs the result back in both civil and minor criminal cases. But, they do not have direct relation with Enashma institution. Even, the striking finding of the study is that the woreda 
formal court adapted the mechanism of searching for truth through oath taking ritual that helped them to minimize the potential occurrences of false witness. To this end, the oath taking materials that have been used in Enashma institution for centuries were recently taken to court and are now serving there.

Enashma institution has many advantages over the formal court system. These include; its usefulness in revealing truth that enhance enduring resolution and reconciliation, its strength in identifying guilty and innocent, and its spiritual sanction on the wrongdoers who offend people secretly. The study demonstrated that these advantages contribute to the persistence use of Enashma institution for conflict resolution in the area.Enashma institution has also some weaknesses such as limited participation of women/genderbiased and lack of standardized rule to fix amount of compensation.

To Sum up, Enashma traditional conflict resolution institution of Boro-Shinasha people played a pivotal role to maintain peace and security in the study area. Therefore, the Enasham institution of Boro-Shinasha inBullen woreda is still widely exist and respected within the community. The institution has different levels such as Bura, Nemma, Terra and Falla. The institution is cost and time effective in addition to many other benefits provide for the community when we compare with the formal court system. Thus, at this time woreda court encourages Enashma institutions to promote peace and to solve conflicts at the grass root level.

\section{References}

Abebe Ano, The Luba Basa Institution: The Challenge on Shinasha Identity. Department of History and Heritage Management, College of Social Sciences, Wollega University Ethiopia, 2012.

Abebe Ano, The Shinasha Relation with other Gonga People. Department of History and Heritage Management, College of Social Sciences, Wollega University Ethiopia, 2012.

Abebe Anno and Adisu Adame, Boro-Shinasha Short Story and Cultural Values. A book Published in Tigi Printing press in Amharic, Assossa, 200.

Abebe Domewoz, The role of Sidama Indigenous Institution in Conflict Resolution: In the Case of Dalle Wored. Southern Ethiopia, Dilla University, Ethiopia, 2016.

Abebe D. Samson S. and Tessema G,Indigenous Conflict Resolution Mechanisms among the Kembata Society;Department of Anthropology, Dilla University, Dilla, Ethiopia, 2015

Abraham M and Yasin M, Vision: Preparatory Civic and Ethical Education for grade 11 and 12.Berekti Prenting Press, Addis Ababa, Ethiopia, 2007.

Abu Ibrahim, Indigenous Mechanisms of Dispute Resolution Among the People of Adaboya Traditional Area. University for Development Studies WA Campus, 2014.

Adisu Adame,History and Culture of Shinasha Society 1992, in Amharic, Bullen, Unplished, 200.

Alemu Amar,Conflict Resolution and Management Skill. Published Book, 2009.

Aseffa A, Indigneous Mechanisms for the Prevention and Resolution of Conflict:The Experience of Oromo in Ethiopia. A Report of Ethiopian National Work Shop, Addis Ababa, Ethiopia, 2001.

Bamlak Yideg, Assessment of Indigenous Conflict Resolution Systems and Practices: Implication for Socio-Economic Development: A Survey of Simada Woreda. Amhara Region, Ethiopia, Mekelle University, 2013.

Bayisa B. and Lemessa D, Coustomary Dispute Resolution in Benishangul Gumuz with Empasis on Shinasha Society. Center Francias des e'tudes e'thiopionnes, 2008. 
Berihun Mebrate,"Spontaneous Settlement and inter-Ethnic Relations in Metekel, North West Ethiopia." M.A. Thesis, Department of Social Anthropology, Addis Ababa University, 1996.

Brad Evans, Types of Conflict-Four Classification, 2013.

Charles Webel and Dvid Barash, Hand books of peace and conflict studies, 2002.

Coser Lewis, "Conflict, Social Aspect" in International Encyclopedia of the Social Science, V.3. The Macmillan Company and Free Press, 1968.

Dejene A. and A. Abdurahman,The Root Causes of Conflict among the Southern Pastoral Communities of Ethiopia: A Case Study of Borana and Degodia. Report of Ethiopia National Workshop. Addis Ababa OSSREA, 2002.

Dereje Seyom, "The Role of Local Government in conflict Management: The case of MESo Woreda." Institute for peace and security Studies in Collaboration with Friedrich Stiftung Addis Ababa, Ethiopia, 2010.

Dejene Gemehu,"Some aspects of Conflict and Conflict Resolution among Waliso Oromo of Eastern Macha, With Particular emphasis on the Guma." M.A. Thesis, Department of Social Anthropology, AddisAbaba University, Addis Ababa Ethiopa, 2002.

Dejene Gemechu, Some Aspects of Conflict and Conflict Resolution Among Waliso Oromo of Eastern Macha, With Particular Emphasis on the Guma. Addis Ababa University, Addis Ababa, Ethiopia, 2002.

Demissie Gudisa,"Social Networks, Conflict and Indigenous Conflict Resolution Mechanisms Among the Derba Oromo of North Shewa." M.A Thesis, Addis Ababa University, Addis Ababa, Ethiopia, 2005.

Esayas Awash (2015)Indigenous Conflict Resolution Institutions: A Study among the Gofa People of the Demba Gofa District, SNNPR. Addis Ababa University, Addis Ababa, Ethiopia, 2015

Endalew Lijalem, Ethiopian Customary Dispute Resolution Mechanisms, 2014.

Evans Pritchard,The Nuer: A Description of the Mode of Livelihood and Political Institutions of Nilotic People. New York: Oxford University Press, 1940.

Gebreyesus Teklu, Popular Dispute Resolution Mechanisms in Ethiopia: Trends, Opportunities, Challenges and Prospects, 2014.

Jemila Adem, Women and Indigenious Conflict Resolution Institution in Oromia: Experiencefrom Siinqee of the Wayyu Shanan Arsi Oromo in Adami Tullu Jiddu Kombolcha District of the Oromia National Regional State:A Thesis Submitted to School of Graduate Studies, Addis Ababa, Ethiopia, 2014

Johan Gultung, Peace by peaceful means: Peace and conflict, development and civilization, 2002.

Peter Wallestineen,Understanding of conflict resolution: war, peace and the global system Ruibas G. and Martinez F. (2014). "Exhibiting Cultures of Contract: A Museum for Benishangul Gumuz, Ethiopia" Department of Pre historic, Universal Complutense de Madrid, StandfordJournal of Archaeology, 2014.

Shail Arora,Formal and Informal Dispute Resolution, 2015.

Tessema Ta'a,The Oromo of Wollega: A History. M.A. Thesis. Department of History, Addis Ababa University, Ethiopia, 2002.

Tsega Endalew,Conflict Resolution Through Cultural Tolerance: Analysis of the Michu: Institution in Metekel Region, Ethiopia”. Social Science Research Report Series, Wollega University, Post Box No: 44, Gimbi, Ethiopia, 2002.

Tsega Endalew: Luba Basa And Hrma Hodha. Traditional Mechanisms of Conflict Resolution in Metekel. Ethiopia, 2008.

Tilahun Seyoum,Wido Inheritance and Women's Rights: The Case of the Boro-Shinasha in Bullen woreda, Benishangul Gumuz Regional State. Addis Ababa University, Addis Ababa, Ethiopia, 2015. 
Uthman Hassen, " The Role of the Abegar (Devine Father) in Conflict Resolution: The Case of Northern Wollo." In Tarekegn Adebo and Hanna Tsadik. Making Peace in Ethiopia: Five Cases of Traditional Mechanisms for Conflict Resolution. Addis Ababa, Peace and development Committee, 2008.

White, Leslie, 2008. 'The Reemergence of Evolutionary Thought: Energy and the Evolution ofCulture'. In, Jon R. McGee and Richard L. Warms. Anthropological Theory: Anintroductory. (4th edition). New York: Frank Mortimer.

Wodisha Habite, Neema Traditional Conflict Resolution Mechanism of Boro- Shinasha people North West Ethiopia: Challenges and Prospects. Addis Ababa Unversity, Addis Ababa, Ethiopia, 210.

Pr. Yalew Endawok,Basic Research Principles and Implementation, A Book Published by Tefera Seyoum Printing Press in Amharic, Addis Ababa, Ethiopia, 2017.

Yonas Berhe,An assessment of indigenous conflict resolution mechanisms of Mezard in rural Almata woreda: Tigray National Regional State, Ethiopia, 2012.

Zegale Tamir,Indignous Institutions as an Alternative Conflict Resolution Mechanisms in Eastern Ethiopia: The Case of the Ittu Oromo and Issa Somalia Clans. Ethiopia, 2016. 